\title{
AMISULPIRIDE INDUCED ERYTHEMA MULTIFORME: A CASE REPORT
}

\author{
S. Arun ${ }^{1}$, A. John Dinesh ${ }^{2}$, S. Alok Pandey 3
}

\section{HOW TO CITE THIS ARTICLE:}

S. Arun, A. John Dinesh, S. Alok Pandey. "Amisulpiride Induced Erythema Multiforme: A Case Report". Journal of Evolution of Medical and Dental Sciences 2014; Vol. 3, Issue 40, September 01; Page: 10053-10056, DOI: $10.14260 /$ jemds/2014/3303

ABSTRACT: Antipsychotic agents being used for schizophrenia accounts to cause adverse cutaneous reactions in approximately $5 \%$ of the individuals. Erythema multiforme caused by amisulpride therapy in a schizophrenic patient is not a commonly seen side effect. Reversal of lesion was seen after stopping the amisulpride which emphasized the cause of Erythema Multiforme.

KEYWORDS: Antipsychotics agents; Schizophrenia; Erythema multiforme.

INTRODUCTION: Atypical antipsychotics have specific characteristics with minimum side effects and found to be more effective than conventional drugs in the treatment of negative symptoms in schizophrenia.

The cutaneous side effects of antipsychotic drugs are well known. They range from anaphylaxis, erythema multiforme, photosensitivity, licheniform, psoriasiform, pitiryasiform, Steven Johnson syndrome, skin pigmentation, a lupus-like fixed drug eruption, seborrhoea and pseudolymphomatous eruption. ${ }^{10-11}$ The drugs implicated are phenothiazines (especially chlorpromazine), thiothixene, fluphenazine, fluspirilene, loxapine and levomepromazine.2-5 We hereby report the following case of Erythema multiforme due to amisulpride in a patient with residual schizophrenia.

CASE REPORT: A 38 years old female from lower socio economic status pre morbidly introvert with family history of schizophrenia in first degree relative presented with past h/o acute onset of psychosis 15years back and was treated with first generation antipsychotics with partial improvement.

Compliance was poor and had multiple relapses on stopping the treatment. On evaluation patient found to have predominant negative symptoms of avolition, apathy, decreased social interaction, reduced speech output and decreased personal care with occasional muttering and smiling to self. No medications were taken sine 6 months.

Rating scales BPRS and SANS was administered. Residual schizophrenia was diagnosed and started on Amisulpiride 50mg and Lorazepam 2mg for sleep. Routine blood investigations (CBC, RBS, RFT) were done which came out normal and no abnormality found on detailed clinical examination. Dose of Amisulpiride was slowly titrated to $200 \mathrm{mg}$. After 10days of in-patient stay, patient showed some improvement and was discharged.

On the day of follow up, patient came with complaint of maculo-papular lesions over upper limbs, neck and trunk since 5days. Patient denied of using new cosmetics, other drugs and the Compliance also found being regular. Dermatologist opinion was sought, diagnosed it as Erythema Multiforme and prescribed anti-histaminergic agents with the advice to stop amisulpiride. Patient was reviewed after 1 week, no lesions were found. 
Rechallenge with amisulpirde wasn't done as patient refused to continue Amisulpiride. Tablet Aripiprazole $5 \mathrm{mg}$ was started and increased to $30 \mathrm{mg}$ with Lorazepam $2 \mathrm{mg}$. Patient was seen on regular follow up with good improvement in symptoms and no adverse reactions were noted.

DISCUSSION: Amisulpride is a substituted benzamide derivative and a highly selective presynaptic dopamine D2/D3 receptor blocker. It has unique dose dependent efficacy, at low dose (50-100 $\mathrm{mg} /$ day) by enhancing dopamine transmission possibly improve negative symptomatology; whereas at higher doses (500-800 mg/day) antagonize postsynaptic D2/D3 receptors, thereby inhibiting dopamine transmission and possibly improving positive symptomatology. ${ }^{7}$

In our case, as the patient had predominant negative symptoms, amisulpiride was started at low dose and given at 200mg. on the third week of drug exposure patient developed maculo-papular lesions which was diagnosed by consultant dermatologist as Erythema Multiforme. There are no well-designed studies, evaluated the cutaneous side effects of amisulpiride but cases have been reported.

A Pityriasisform eruption was reported with low dose of amisulpiride 50mg within a week of starting the tablet ${ }^{9}$. In another report long duration of exposure to amisulpiride found to cause Flagellata erythema followed by pigmentation and photosentivity ${ }^{1}$. It has been postulated that tablet Amisulpride given for long duration cause pathogenesis of photosensitivity. The lesion caused by antipsychotics is cumulative effects and caused by the post-inflammatory effects of amisulpride to the cutaneous vessels. ${ }^{8}$

CONCLUSION: Despite being considered as low side effect profile drug, regular monitoring for adverse reaction is required for starting amisulpiride. A well designed study is required to validate the results of these case studies.

\section{REFERENCES:}

1. Misra a k, Nagpure s. A case report of amisulpride induced flagellate erythema followed by pigmentation and photosensitivity in a schizophrenic patient. Asian J Pharm Clin.2013; 6 (1): 163-164

2. Bhatia MS, Choudhary S, Khanna S, Agarwal P. Cozapine-induced pityriasiform eruption. Indian J Dermatol 1997; 42: 245-246.

3. Bond WS, Yee GC. Ocular and cutaneous sideeffects of chronic phenothiazine therapy. Am J Hosp Pharm 1980; 31: 74-78.

4. Breathnach SM, Hunter $H$. Adverse drug reactions and the skin. Blackwell Scientific Publications, Oxford, 1992; 202-203.

5. Gupta MA, Gupta AK, Hiberman HF. Psychotropic drugs in dermatology, a review and guidelines for use. J Am Acad Dermatol 1986; 14: 634-645.

6. Hagermack O, Wennerslen G, Almeyda J. Drug reactions XIV. Cutaneous side-effects of phenothiazines. Br J Dermatol 1971; 84: 605-607.

7. Kerwin R. From pharmacological profiles to clinical outcomes. Int Clin Psychopharmcol. 2000; 15: S1-4.

8. Laurence Borras, Philippe Huguelet. A Case Report of Photosensitivity to Amisulpride. Prim Care Companion J Clin Psychiatry. 2007; 9 (2):153. 


\section{CASE REPORT}

9. Bhatia M S, Chaudhary G. Amisulpride Induced Pityriasiform Eruption. Delhi Psychiatry Journal 2007;10: (2)

10. Simpson GM, Pi EH, Srajnek JJ, Jr. Adverse effects of antipsychotic agents. Drugs 1981; 21:138151.

11. Warnock JK, Morris DW. Adverse cutaneous reactions to antipsychotics. Am J Clin Dermatol. 002; 3: 629-636.

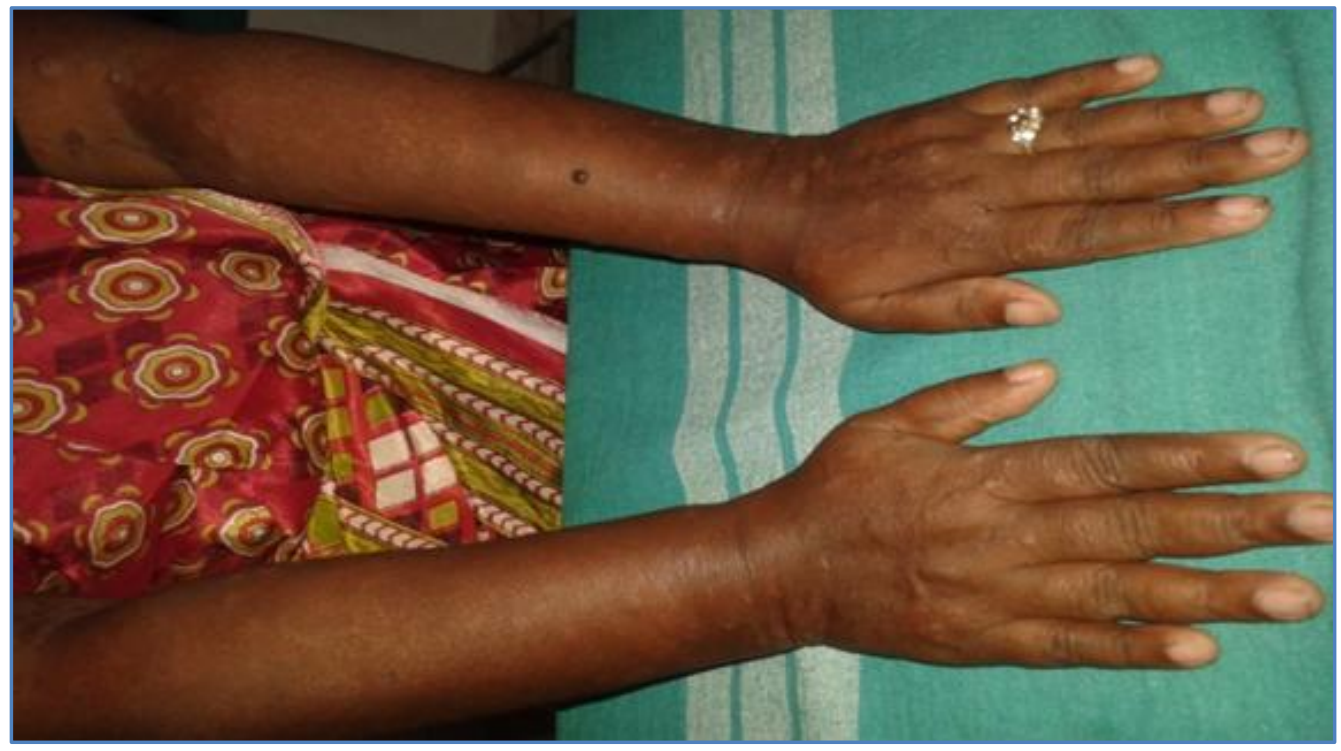

Fig 1: amisulpride induced edematous papules in upper extremities

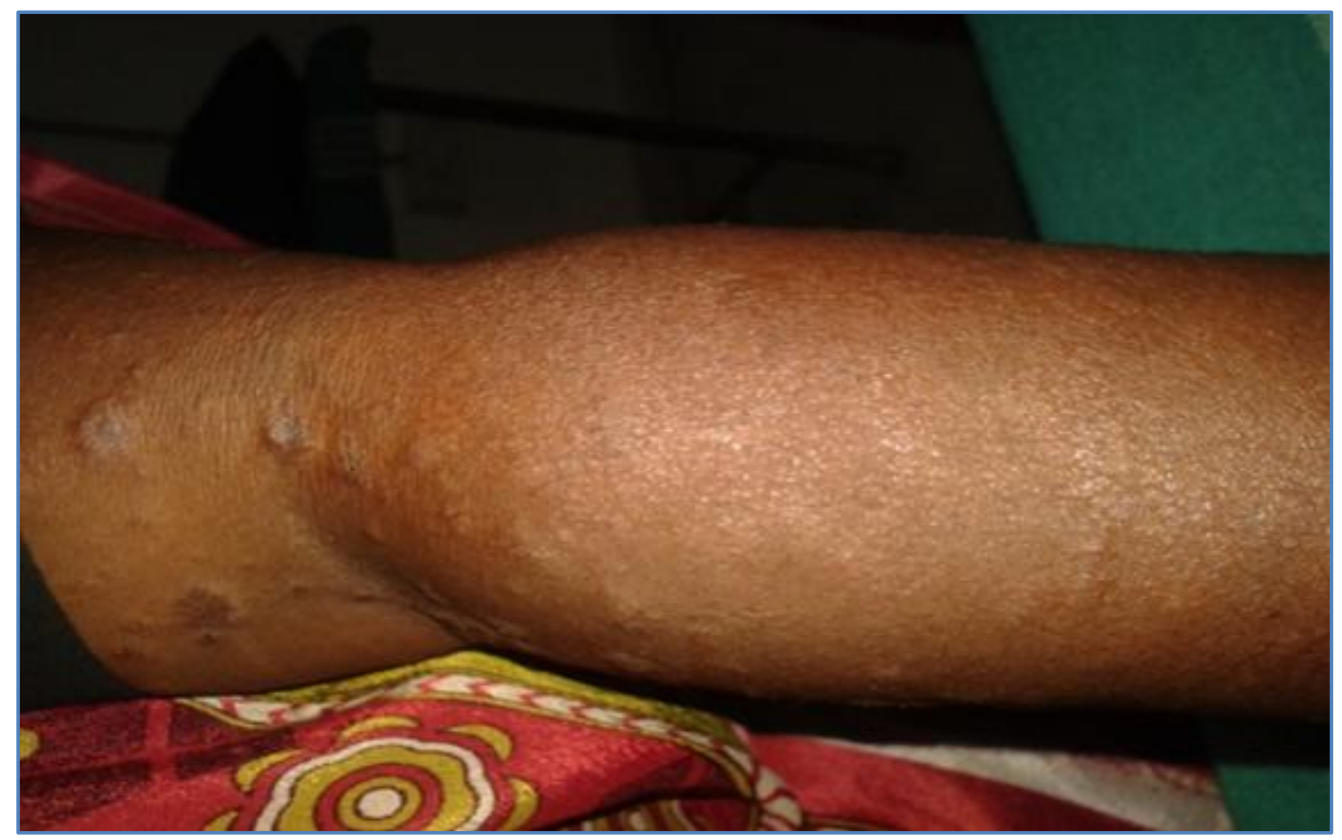

Fig 2: Amisulpride induced edematous papules (erythema multiforme) 


\section{CASE REPORT}

\section{AUTHORS:}

1. S. Arun

2. A. John Dinesh

3. S. Alok Pandey

\section{PARTICULARS OF CONTRIBUTORS:}

1. Assistant Professor, Department of Psychiatry, Sri Venkateshwarra Medical College Hospital \& Research Center.

2. Assistant Professor, Department of Psychiatry, Sri Venkateshwarra Medical College Hospital \& Research Center.

3. Professor, Department of Psychiatry, Sri Venkateshwarra Medical College Hospital \& Research Center.

\section{NAME ADDRESS EMAIL ID OF THE} CORRESPONDING AUTHOR:

Dr. A. John Dinesh,

Assistant Professor,

Department of Psychiatry,

Sri Venkateshwaraa Medical College

Hospital and Research Center,

Ariyur, Pondicherry.

Email: dr.johndinesh@gmail.com

Date of Submission: 21/08/2014.

Date of Peer Review: 22/08/2014.

Date of Acceptance: 26/08/2014.

Date of Publishing: 29/08/2014. 